\title{
DFT studies on the structure and stability of tetraaza macrocyclic nickel(II) complexes containing dicarbinolamine ligand moiety
}

\author{
E J PADMA MALAR ${ }^{\mathrm{a}, *}$ (D, REBECCA JACOB ${ }^{\mathrm{b}}$ and S BALASUBRAMANIAN ${ }^{\mathrm{c}}$ \\ a National Centre for Ultrafast Processes, University of Madras, Taramani Campus, Chennai, \\ Tamilnadu 600025, India \\ ${ }^{\mathrm{b}}$ School of Chemistry, University of Sydney, Sydney, NSW 2006, Australia \\ ${ }^{\mathrm{c}}$ Department of Inorganic Chemistry, University of Madras, Guindy Campus, Chennai, Tamilnadu 600025 , \\ India \\ E-mail: ejpmalar@yahoo.com
}

MS received 26 April 2019; revised 10 July 2019; accepted 30 July 2019; published online 8 November 2019

\begin{abstract}
Density functional theory calculations at M052X/6-311++ $\mathrm{G}^{* *}$ level were performed to understand the structure and stability of $\mathrm{Ni}$ (II) tetraaza macrocyclic dicarbinolamine complex $\mathbf{1}$. The preferential stability of $\mathbf{1}$ over the hitherto unknown $\mathrm{Ni}$ (II) complex having fully conjugated macrocyclic ligand $\mathbf{2}$, is examined by analyzing geometric and electronic structures and energy considerations. The present calculations predict that in the trans $\left(C_{2}\right)$ structure, $\mathbf{1}$ is $102 \mathrm{kcal} / \mathrm{mol}$ more stable than its components 2 and $2(\mathrm{OH})$ at M062X-D3/def2-QZVP//M052X/6-311++G** level. This significant stabilization explains the formation of $\mathbf{1}$ as experimentally observed. The calculations support a distorted square planar environment for $\mathrm{Ni}$ in $\mathbf{1}$, in agreement with the observed spectral and magnetic properties. In order to understand the stability of $\mathbf{1}$, we examined the second-order stabilizing interactions in natural bond orbital (NBO) basis, the role of the noncovalent dispersion energy, macrocyclic cavity size, Ni-ligand covalent bond strength, natural electronic population on the atomic centers and the nature of the frontier molecular orbitals in the complexes. The present study reveals that the higher stability of $\mathbf{1}$ over $\mathbf{2}$ is primarily due to the stronger covalent bonds between the $\mathrm{Ni}$ (II) centre, and two of the coordinating nitrogen atoms in $\mathbf{1}$ than in $\mathbf{2}$ and significant secondorder stabilizing interactions originating from the NBOs involving the oxygen atoms.
\end{abstract}

Keywords. $\mathrm{Ni}(\mathrm{II})$ macrocyclic dicarbinolamine complex; Ni-ligand covalent bond strength; M052X/6$311++\mathrm{G}^{* *}$; dispersion energy; natural electronic population; macrocyclic cavity size.

\section{Introduction}

Many macrocyclic complexes of transition metals and lanthanides are useful models for naturally occurring systems such as the heme and non-heme proteins and metalloenzymes. ${ }^{1-9}$ Macrocyclic polyaza complexes are extensively studied because of their biological properties and their importance in coordination chemistry. ${ }^{10-15}$ They also find applications as magnetic resonance imaging agents, radioimmuno therapeutic agents, and in color switches. ${ }^{16-20}$ The redox potentials of these systems can be altered by making suitable modifications in their structures and some of these are useful in the electrochemical reduction of $\mathrm{CO}_{2}{ }^{21}$
The macrocyclic hole size in the highly conjugated macrocyclic ligand is smaller than that in the corresponding saturated system. Metals bind strongly with the macrocycles having a cavity that fits its size best. $^{22-25}$ The saturated ligands can exist in different structures due to conformational flexibility in the macrocyclic subunits. Configurational isomers of metal complexes with saturated tetraaza macrocycle tetramethylcyclam were isolated. ${ }^{26,27}$ It is found that the cyclam (cyclam $=1,4,8,11$-tetraazacyclotetradecane) complexes of $\mathrm{Ni}(\mathrm{II}), \mathrm{Co}(\mathrm{III})$ and $\mathrm{Cr}(\mathrm{III})$ possess energetically most favorable trans-III configuration having the least ring strain. ${ }^{28-34}$ In this structure, the two sixmembered chelating rings in the complex exhibit chair

*For correspondence

Electronic supplementary material: The online version of this article (https://doi.org/10.1007/s12039-019-1688-4) contains supplementary material, which is available to authorized users. 
form. On the other hand conjugated macrocyclic ligands such as the porphyrins lead to planar structure of the metal complexes. ${ }^{1,9}$

Though macrocyclic polyaza complexes have received considerable attention, only a few cases are reported with dicarbinolamine moiety in the macrocyclic ligand. ${ }^{35-41}$ Dicarbinolamine complex $\mathbf{1}$ (scheme 1) and its methyl derivatives synthesized were reported to be diamagnetic and non-ionic in nature. $^{39}$ The tetraaza 14-membered macrocyclic ligand in these complexes are conjugated with the exception of the region containing the two equivalent $\mathrm{sp}^{3}$ carbon atoms each having a hydroxyl and phenyl substituents, since the macrocyclic part is less flexible as it is highly conjugated. Thus, the macrocyclic part can exist in a planar structure unlike in the case of the fully saturated cyclam complexes which adopt different conformations. ${ }^{26,27}$ However, the two hydroxyl groups can adopt trans or cis arrangement with reference to the macrocyclic ring leading to the $C_{2}$ and $C_{\mathrm{s}}$ structures of $\mathbf{1}$. Due to steric effects arising from the bulky phenyl substituents, the macrocyclic part in $\mathbf{1}$ will possess a distorted planar structure. The failure to obtain the corresponding fully conjugated compound $\mathbf{2}$ led to the inference that the dicarbinolamine complex $\mathbf{1}$ is stabilized due to electronic and structural effects that originate from the orientation of the phenyl groups present. $^{39}$

Although the spectral, magnetic, and conductance studies led to the characterisation of $\mathbf{1}$ as a squareplanar nickel(II) complex, ${ }^{39}$ the structure of $\mathbf{1}$ was not determined by X-ray analysis. In the present study, we examined the structure of the dicarbinolamine complex 1 by complete structural optimization using the density functional theory (DFT) methods. The formation of the $\mathrm{Ni}$ (II) complex containing the dicarbinolamine ligand moiety $\mathbf{1}$ was rationalized by examining the relative stability in the experimentally observed complex 1 and the hitherto unknown system 2 with the fully conjugated 14-membered tetraazamacrocyclic ligand (Scheme 1). In order to understand the role of the phenyl substituents in stabilizing the Nickel complex with the dicarbinolamine moiety, we also investigated the complexes $\mathbf{3}$ and $\mathbf{4}$ wherein $\mathrm{R} 1=\mathrm{R} 2=\mathrm{R} 3=\mathrm{R} 4=\mathrm{H}$ (Scheme 1). The electronic and molecular structures of the complexes 1, 2, 3 and 4 were compared using different density functional theory (DFT) methods. ${ }^{42}$ The DFT method BP86 $6^{43,44}$ is reported to be suitable to study transition metal complexes. ${ }^{33,34,45-48}$ However, recent studies reveal the importance of noncovalent dispersion forces ${ }^{49}$ in stabilizing sterically hindered metal complexes. ${ }^{50-52}$ The complexes $\mathbf{1}$ and $\mathbf{2}$ under study contain four bulky phenyl substituents and hence it is appropriate to study these systems using the DFT methods such as the M052X $\mathrm{X}^{53}$ and M062X-D3 ${ }^{54-56}$ which take into account the noncovalent interactions. ${ }^{57}$ Benchmark study by Goerigk and Grimme ${ }^{56}$ has proved by statistical analysis that the M062X-D3 is the best hybrid DFT method to study noncovalent dispersion interactions in varied types of systems. Application of the above methods at M052X/6-311++ $\mathrm{G}^{* *}$ and M062XD3/def2-QZVP levels on alanine dimers yielded accurate binding energies. ${ }^{58}$ Though the B3LYP ${ }^{59,60}$

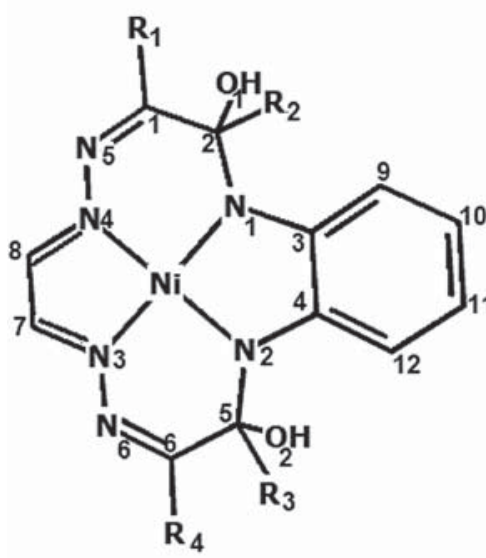

$1 \mathrm{R}_{1}=\mathrm{R}_{2}=\mathrm{R}_{3}=\mathrm{R}_{4}=\mathrm{Ph}$

$3 \mathrm{R}_{1}=\mathrm{R}_{2}=\mathrm{R}_{3}=\mathrm{R}_{4}=\mathrm{H}$

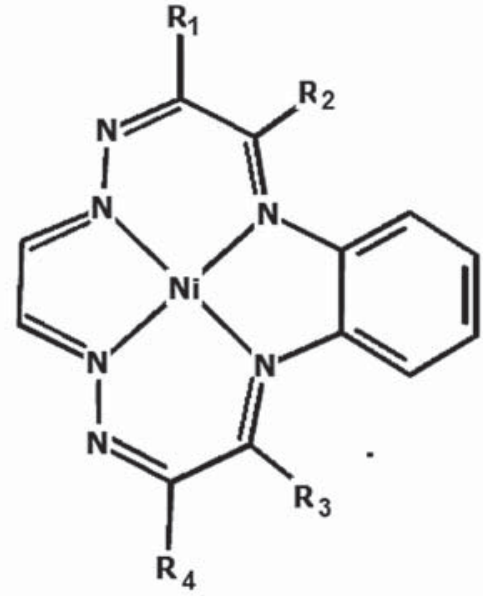

$2 \quad \mathrm{R}_{1}=\mathrm{R}_{2}=\mathrm{R}_{3}=\mathrm{R}_{4}=\mathrm{Ph}$

$4 \quad R_{1}=R_{2}=R_{3}=R_{4}=H$

Scheme 1. Ni(II) complexes studied. 
functional is widely used in investigations of molecular electronic structure, it has been reported that the B3LYP method is not suitable to study the noncovalent interactions. ${ }^{55,56}$

\section{Computational aspects}

The molecular geometries and electronic structures in the low-spin neutral complexes 1-4 were examined by complete structural optimization using the DFT methods M052X/6-311++G** and M052X/TZVP level. We also performed the BP86/def2-TZVP and the B3LYP/6-31G* calculations for comparison. The metal-ligand bonding was examined by analyzing the Mayer's covalent bond orders $^{61-63}$ obtained at single-point M062X-D3/def2-QZVP calculations performed on the different optimized geometries of the complexes. The M052X and B3LYP calculations were carried out using the Gaussian 03 software. ${ }^{64}$ The BP86 and M062X-D3 calculations invoked the Resolution of Identity (RI) algorithm ${ }^{65}$ to enhance the efficiency of the calculations. The def2-TZVP and def2-QZVP basis sets used in the BP86 and M062X calculations are the extended polarized basis set TZVPP and QZVPP, respectively, on the atoms other than hydrogen. ${ }^{66}$ Further, Auxiliary Coulomb fitting basis sets ${ }^{67}$ def2/J were added to the def2-TZVP and def2-QZVP basis sets for accurate predictions. We have used the ORCA 4.0.1 software $^{68,69}$ for performing the BP86 and M062X calculations as the def2-TZVP, def2-QZVP and the auxiliary Coulomb fitting basis sets were incorporated in ORCA.

\section{Results and Discussion}

The structural optimization reveals that the complexes $\mathbf{1}, \mathbf{2}$ and $\mathbf{3}$ can exist in $C_{2}$ and $C_{\mathrm{s}}$ point groups. The $C_{2}$ axis of symmetry passes through the $\mathrm{Ni}$ and centres of the carbon-carbon bonds $\mathrm{C} 3-\mathrm{C} 4, \mathrm{C} 10-\mathrm{C} 11$ and C7-C8 (Figures 1 and 2). In the $C_{\mathrm{s}}$ structure, the symmetry plane passes through $\mathrm{Ni}$ and bisects the bonds $\mathrm{C} 3-\mathrm{C} 4, \mathrm{C} 10-\mathrm{C} 11$ and $\mathrm{C} 7-\mathrm{C} 8$ (Figures 1 and 2). The pair of hydroxyl groups in $\mathbf{1}$ and $\mathbf{3}$ are in transarrangement with reference to the macrocyclic ligand plane in the $C_{2}$ structure (Figures 1a and 1c) and cis in the $C_{\mathrm{s}}$ geometry (Figures $1 \mathrm{~b}$ and $1 \mathrm{~d}$ ). It is seen that in the complexes $\mathbf{1}$ and $\mathbf{2}$, the phenyl groups $\mathbf{A}$ and $\mathbf{A}^{\prime}$ as well as $\mathbf{B}$ and $\mathbf{B}^{\prime}$ are in transarrangement with reference to the macrocyclic ligand plane in the $C_{2}$ structure (Figures 1a and 2a) and cis in the $C_{\mathrm{s}}$ geometry (Figures $1 \mathrm{~b}$ and $2 \mathrm{~b}$ ). The fully conjugated complex $\mathbf{4}$ is found to be planar and exhibits $C_{2 \mathrm{v}}$ point group in its lowest energy structure. The optimized structural parameters in 1, 2, 3 and 4 obtained by the different DFT methods are compared in Tables S1, S2, S3 and S4 (Supplementary Information), respectively. The results indicate that in 1, 2, 3 and 4 the nickel - nitrogen coordinate bonds Ni-N1, Ni-N2, Ni-N3 and Ni-N4 have lengths in the range $1.83-1.89 \AA$. Due to the symmetry in the complexes the bond lengths of Ni-N1 and Ni-N2 are equal. Similarly Ni-N3 and Ni-N4 have same lengths. The N...N lengths in the coordinating region vary from 2.52 to $2.73 \AA$. The bite angles N1-Ni-N2 and N3-Ni-N4 involving the five-membered chelating rings are in the range $84-88^{\circ}$. As expected, the bite angles in the six-membered chelating rings $\mathrm{N} 2-\mathrm{Ni}-\mathrm{N} 3$ and $\mathrm{N} 3-\mathrm{Ni}-\mathrm{N} 4$ are wider in the range $93-95^{\circ}$. The coordinating nitrogen atoms $\mathrm{N} 1, \mathrm{~N} 2, \mathrm{~N} 3$ and $\mathrm{N} 4$ are coplanar in the $C_{\mathrm{s}}$ and $C_{2 \mathrm{v}}$ structures as revealed by the dihedral angle N1N2N3N4 $=0^{\circ}$. However, in the $C_{2}$ point group of $\mathbf{1}, \mathbf{2}$ and $\mathbf{3}$, the donor nitrogen atoms are nearly planar and the magnitude of the dihedral angle N1N2N3N4 is found to vary up to $5^{\circ}$. The Ni(II) centre deviates by about $2^{\circ}$ from the plane of the coordinating nitrogen atoms. Thus, it is evident that the $\mathrm{Ni}$ (II) and the four chelating nitrogen atoms exhibit distorted square planar geometry in the complexes 1, 2, 3 and $\mathbf{4}$ as observed experimentally for the complex $\mathbf{1}^{39}$

\subsection{Structure of the dicarbinolamine complexes 1 and $\mathbf{3}$}

The M052X/6-311++G** optimized geometries with selected structural parameters of the nickel dicarbinolamine complexes $\mathbf{1}$ and $\mathbf{3}$ are shown in Figure 1. It is seen from Figure 1 and Tables S1 and S3 (Supplementary Information) that the optimized structural parameters in the $C_{2}$ and $C_{\mathrm{s}}$ geometries do not change to any significant extent in a given DFT method. The results predicted at the M052X/6$311++\mathrm{G}^{* *}$ and M052X/TZVP are very similar. The M052X methods predict the Ni-N1 and Ni-N2 bond lengths of $\sim 1.84 \AA$ in $\mathbf{1}$ and $\mathbf{3}$ and are $\sim 0.05 \AA$ shorter than the Ni-N3 and Ni-N4 bonds (of length $1.89 \AA$ ). Although the overall structural features predicted by the BP86 and B3LYP calculations are similar, significant differences are noticed in the nickel nitrogen bond lengths. There is a change in the trend in the BP86/def2-TZVP results which predict $\mathrm{Ni}-\mathrm{N} 1$ and $\mathrm{Ni}-\mathrm{N} 2$ bonds are longer $(\sim 1.86 \AA)$ than the Ni-N3 and Ni-N4 bonds $(\sim 1.84 \AA$ ) in 1 while the four Ni-N lengths are $\sim 1.85 \AA$ in 3. The B3LYP/6-31G* study predicts nearly equal Ni-N bond lengths $(\sim 1.83 \AA)$ in 1 and 3. As the M052X and M062X functionals are 

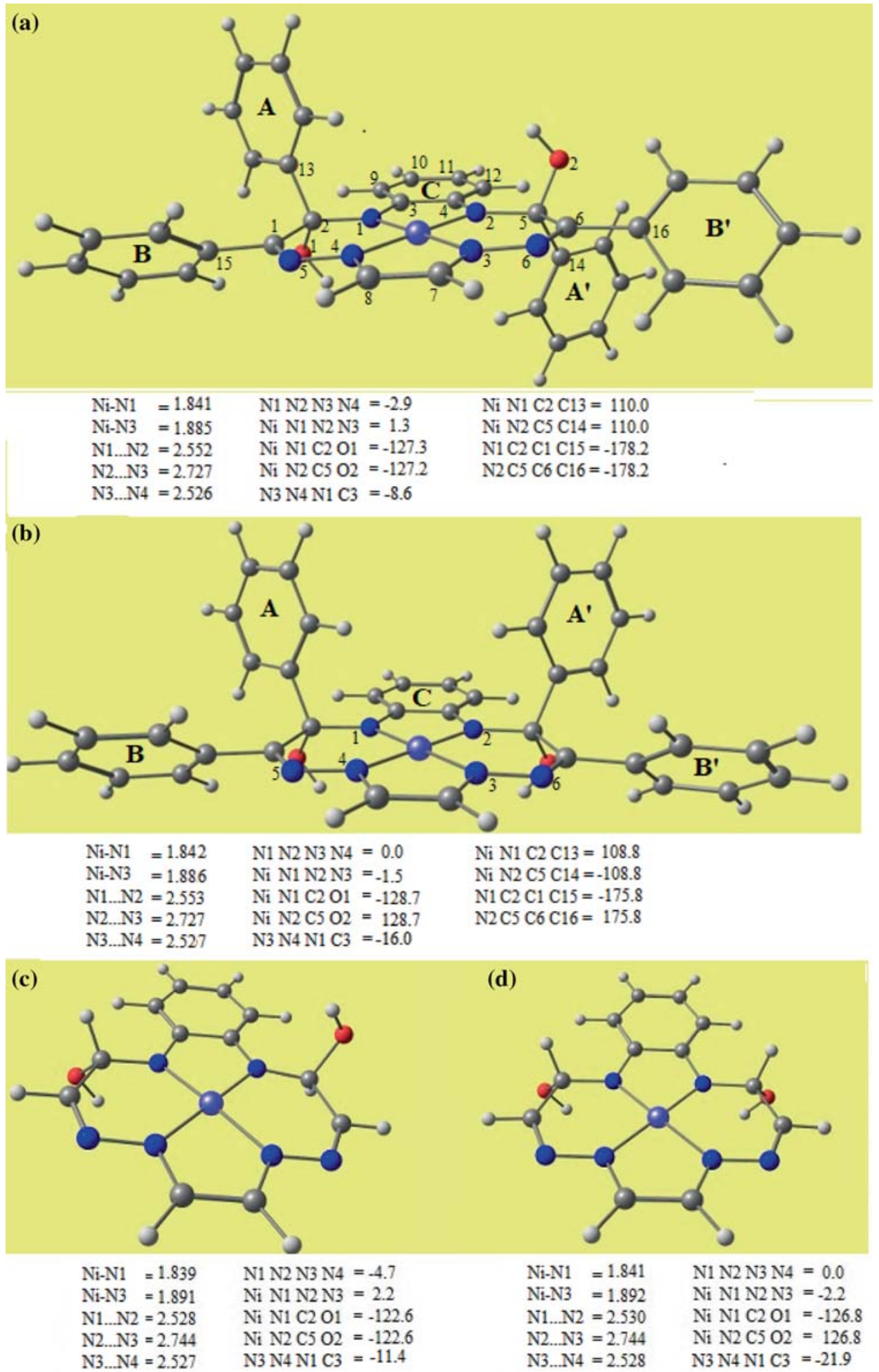

Figure 1. M052X/6-311++G** optimized geometries of (a) $\mathbf{1}\left(C_{2}\right)$, (b) $\mathbf{1}\left(C_{\mathrm{s}}\right)$, (c) $\mathbf{3}\left(C_{2}\right)$ and (d) $\mathbf{3}\left(C_{\mathrm{s}}\right)$. Atomic labels are given in a). Selected bond lengths (in $\AA$ ) and dihedral angles (in ${ }^{\circ}$ ) are shown. Colour code: $\mathrm{Ni}$ - purple; $\mathrm{N}$ - blue; $\mathrm{C}$ - grey; $\mathrm{H}$ - white; $\mathrm{O}$ - red.

found to be suitable to study systems wherein noncovalent interactions play a role $e^{53,56}$ we focus on the results obtained from these methods.
As seen in Figure 1, the hydroxyl groups as well as the adjacent phenyl groups $\mathbf{A}$ and $\mathbf{A}^{\prime}$ which are bonded to the $\mathrm{sp}^{3}$ carbon atoms (C2 and $\left.\mathrm{C} 5\right)$ in the complex $\mathbf{1}$ 

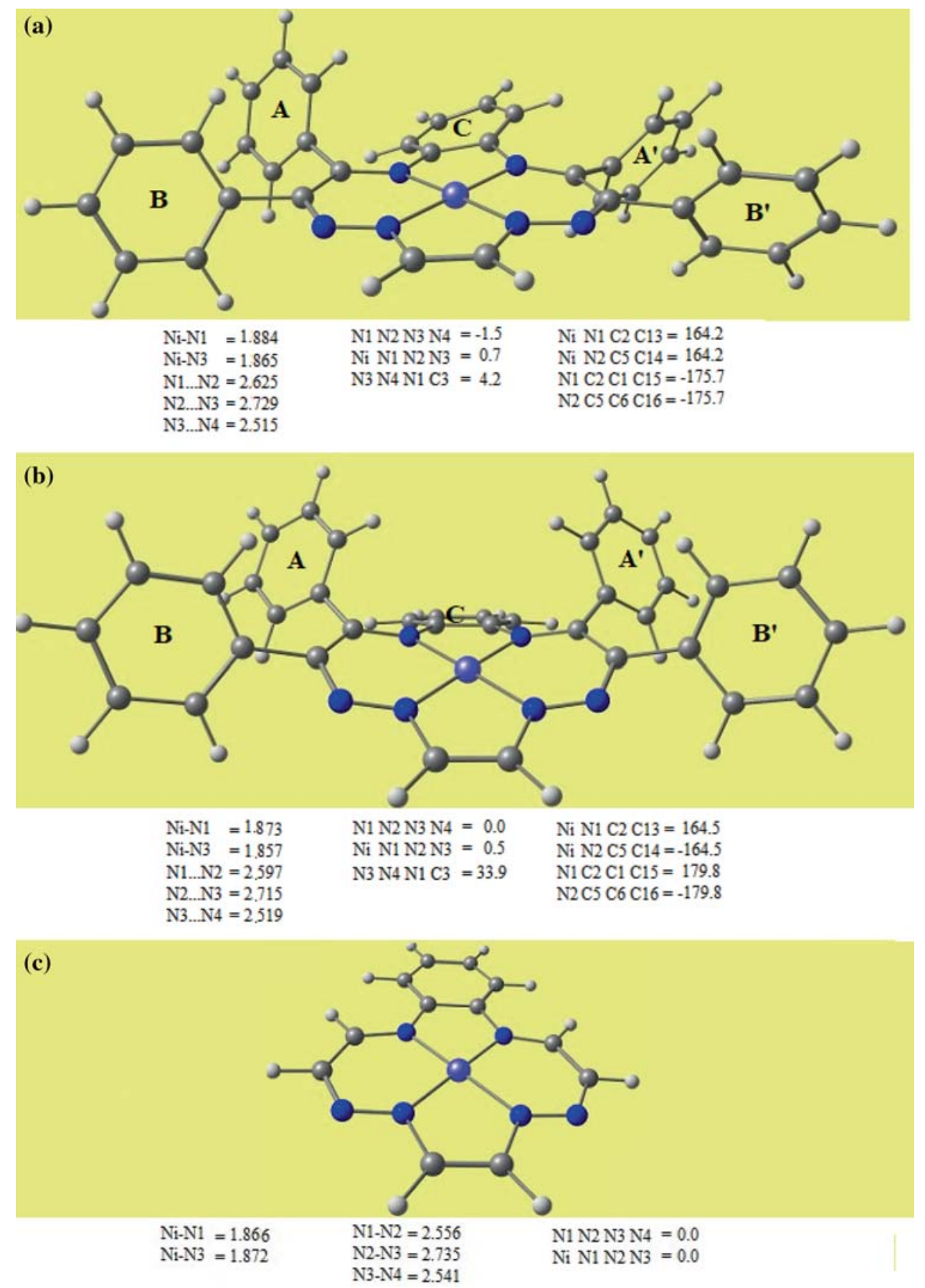

Figure 2. M052X/6-311++G** optimized geometries of (a) $2\left(C_{2}\right)$, (b) $\mathbf{2}\left(C_{\mathrm{s}}\right)$ and (c) $\mathbf{4}\left(C_{2 \mathrm{v}}\right)$. Selected bond lengths (in $\AA$ ) and dihedral angles $\left(\right.$ in $^{\circ}$ ) are shown. Colour code: $\mathrm{Ni}$ - purple; $\mathrm{N}$ - blue; $\mathrm{C}$ - grey; $\mathrm{H}$ - white.

adopt axial-like orientation with reference to the 14-membered macrocycle. However, the phenyls $\mathbf{B}$ and $\mathbf{B}^{\prime}$ are bonded equatorially to the macrocycle as reflected from the dihedral angles $\mathrm{N} 1 \mathrm{C} 2 \mathrm{C} 1 \mathrm{C} 15$ and $\mathrm{N} 2 \mathrm{C} 5 \mathrm{C} 6 \mathrm{C} 16$ which are close to $-180^{\circ}$. It is observed that all the four phenyl groups lie in vertical planes with reference to the macrocyclic ring so that the steric repulsion is minimum.

The macrocyclic ligand units in the dicarbinolamine systems $\mathbf{1}$ and $\mathbf{3}$ are found to be distorted from the planar structure in both $C_{\mathrm{s}}$ and $C_{2}$ point groups. The M052X calculations predict a deviation of $-2.9^{\circ}$ from planarity for the coordinating nitrogen atoms in the $C_{2}$ point group of $\mathbf{1}$ as seen from the dihedral angle N1N2N3N4 while the deviation is $-4.7^{\circ}$ in 3 (Figure 1). In the $C_{\mathrm{s}}$ structure the donor nitrogen atoms are coplanar in $\mathbf{1}$ and $\mathbf{3}$. In $\mathbf{1}$ the carbon atoms $\mathrm{C} 3$ and $\mathrm{C} 4$ in the macrocycle that forms part of the benzo ring deviate from the plane of the coordinating nitrogen atoms by -8.6 and $-16.0^{\circ}$, respectively, in the $C_{2}$ and 
$C_{\mathrm{s}}$ structures as reflected by the dihedral angle $\mathrm{N} 3 \mathrm{~N} 4 \mathrm{~N} 1 \mathrm{C} 3$. It is seen that corresponding dihedral angles in 3 are -11.4 and $21.9^{\circ}$ which reveal that the nonplanarity of the macrocycle is more pronounced in $\mathbf{3}$ than in $\mathbf{1}$ though the bulky phenyl substituents are absent in the former. Thus, it is clear that the hydroxyl groups in $\mathbf{1}$ and $\mathbf{3}$ are mainly responsible for the nonplanarity of the macrocyclic unit. The present study leads to the inference that the presence of the two hydroxyl groups in the cis arrangement leads to a larger deviation from planarity in the $C_{\mathrm{s}}$ structure.

\subsection{Structure of the fully conjugated complexes 2 and 4}

The M052X/6-311++ $\mathrm{G}^{* *}$ optimized $C_{\mathrm{s}}$ and $C_{2}$ geometries of $\mathbf{2}$ and $\mathbf{4}$ are shown in Figure 2. It is seen that the structures of $\mathbf{2}$ and $\mathbf{4}$ differ considerably from those of the corresponding dicarbinolamine complexes $\mathbf{1}$ and $\mathbf{3}$. The phenyl groups $\mathbf{A}$ and $\mathbf{A}^{\prime}$ are equatorially arranged in $\mathbf{2}$ as expected from the $\mathrm{sp}^{2}$ nature of the substituted carbon atoms $\mathrm{C} 2$ and $\mathrm{C} 5$. The close proximity of the phenyl groups $\mathbf{A}$ and $\mathbf{A}^{\prime}$ to the macrocyclic ligand in $\mathbf{2}$ as compared to that in $\mathbf{1}$ leads to a large deviation from planarity in the macrocyclic part near the benzo ring. The benzo ring is titled in the $C_{2}$ structure of 2 while it is bent in the $C_{\mathrm{s}}$ structure such that it is farther from the phenyl groups $\mathbf{A}$ and $\mathbf{A}^{\prime}$ in order to avoid the steric repulsion (Figure 2). In the $C_{\mathrm{s}}$ structure of 2 , the benzo ring carbons $\mathrm{C} 3$ and $\mathrm{C} 4$ deviate from the plane of the chelating nitrogens in the 14-membered tetraaza macrocylic part by $34^{\circ}$ as manifested by the dihedral angle N3N4N1C3. Due to these changes the bond lengths and bond angles show significant differences in the $C_{\mathrm{s}}$ and $C_{2}$ point groups of $\mathbf{2}$, unlike in $\mathbf{1}$ where the structural parameters are quite similar in the two-point groups studied. The titling and bending of the benzo ring in the $C_{2}$ and $C_{\mathrm{s}}$ structures of 2 decrease the delocalization of the $\pi$-electrons of the benzo ring with the donor nitrogen atoms $\mathrm{N} 1$ and N2. This leads to the elongation of the bonds C3-N1, C4-N2, Ni-N1 and Ni-N2 (Figure 2 and Table S2, Supplementary Information) and also reorganization of the macrocyclic unit in $\mathbf{2}$. In contrast to the trend in the Ni-N bond lengths in $\mathbf{1}$ and $\mathbf{3}$, the Ni-N1and Ni-N2 bonds are longer than those of Ni-N3 and Ni-N4 in 2 . Further in the $C_{\mathrm{s}}$ point group, the two six-membered rings in the macrocyclic part in $\mathbf{2}$ exhibit boat like arrangement. This is in contrast to the chair-like conformation adopted by the 6-membered chelating rings in the $\mathrm{Ni}(\mathrm{II})-$ (cyclam) complexes having a saturated macrocyclic part. ${ }^{28-34}$ Comparison of the $C_{2}$ and $C_{\mathrm{s}}$ structures of $\mathbf{2}$ with the lowest energy planar $C_{2 \mathrm{v}}$ structure of $\mathbf{4}$ (in which the phenyl groups $\mathbf{A}, \mathbf{A}^{\prime}$, $\mathbf{B}$ and $\mathbf{B}^{\prime}$ are replaced by hydrogen atoms) reveals that nonplanarity in the macrocyclic part as well as the benzo ring in $\mathbf{2}$ is due to the steric effect of the phenyl substituents.

\subsection{Stability in the dicarbinolamine complexes}

The total energies and the relative energies in the $\mathrm{Ni}$ (II) complexes under study obtained at the different DFT levels are presented in Table 1. The total energies predicted in the $C_{2}$ and $C_{\mathrm{s}}$ structures of 1 by a given DFT level are very close as expected from the very similar structural parameters. It is seen that the variation in the energies is within $\pm 0.3 \mathrm{kcal} / \mathrm{mol}$. A similar trend is predicted in the total energies of the complex 3 as well. The very narrow energy difference between the $C_{2}$ and $C_{\mathrm{s}}$ geometries indicates that the dicarbinolamine complexes can exist in both the structures wherein the two hydroxyl groups adopt trans or cis orientations respectively (Figure 1). Tasker and coworkers ${ }^{38}$ reported the cis arrangement of the hydroxyl groups in the crystal structure of a $\mathrm{Zn}$ (II) dicarbinolamine complex. In $\mathbf{2}$, the $C_{\mathrm{s}}$ structure is found to be the energetically favoured since it is lower in energy than the $C_{2}$ structure by 3 to $5 \mathrm{kcal} / \mathrm{mol}$ at the different DFT levels.

The suitability of the total electronic energies, instead of the free energies, for comparing the stabilities of the $C_{2}$ and $C_{\mathrm{s}}$ structures of the complex was tested by computing the free energies of the complex $\mathbf{3}$ at M06-2X/def2-TZVP//M052X/6-311++G** level (Table S6 in Supplementary Information). The Gibbs free energies are -2445.481174 and -2445.480587 hartree, respectively, in the $C_{2}$ and $C_{\mathrm{s}}$ structures of $\mathbf{3}$ at $298 \mathrm{~K}$. Thus, it is seen that the free energies of the two structures of $\mathbf{3}$ are very close to each other and the complex can exist in both the structures as predicted by the corresponding total energies. The difference of $0.37 \mathrm{kcal} / \mathrm{mol}$ in the free energies of $C_{2}$ and $C \mathrm{~s}$ structures of $\mathbf{3}$ is comparable to the corresponding difference of $0.42 \mathrm{kcal} / \mathrm{mol}$ in the total energies predicted at M06-2X-D3/def2-QZVP//M052X/6-311++ $\mathrm{G}^{* *}$ level (Table 1). This leads to the inference that the relative stabilities are predicted reliably by the total energies.

To understand the formation of the dicarbinolamine complex $\mathbf{1}$ in the experimental study, ${ }^{39}$ we investigated its relative stability, $\Delta \mathrm{E}$, with respect to the components 2 and two $\mathrm{OH}$ radicals using the equation 
Table 1. Total energy, $\mathrm{E}$, in hartree in $\mathrm{Ni}(\mathrm{II})$ complexes $\mathbf{1}, \mathbf{2}, \mathbf{3}$ and $\mathbf{4}$. Relative stability $\Delta \mathrm{E}$ in $\mathbf{1}$ and $\mathbf{3}$ are given in $\mathrm{kcal} / \mathrm{mol} . \Delta \mathrm{E}(\mathbf{1})=\mathrm{E}(\mathbf{1})-\mathrm{E}(\mathbf{2})-2 \mathrm{E}(\mathrm{OH}) ; \Delta \mathrm{E}(\mathbf{3})=\mathrm{E}(\mathbf{3})-\mathrm{E}(\mathbf{4})-2 \mathrm{E}(\mathrm{OH})^{\mathrm{a}}$.

\begin{tabular}{|c|c|c|c|c|}
\hline Method & Complex & Point group & $\mathrm{E}$ & $\Delta \mathrm{E}$ \\
\hline \multirow[t]{7}{*}{$\mathrm{M} 052 \mathrm{X} / 6-311++\mathrm{G}^{* *}$} & 1 & $C_{2}$ & $-3376.071737(0.00)$ & -98.41 \\
\hline & 1 & $C_{\mathrm{s}}$ & $-3376.071880(-0.09)$ & -95.59 \\
\hline & 2 & $C_{2}$ & $-3224.422969(0.00)$ & \\
\hline & 2 & $C_{\mathrm{s}}$ & $-3224.427604(-2.91)$ & \\
\hline & 3 & $C_{2}$ & $-2451.715772(0.00)$ & -84.08 \\
\hline & 3 & $C_{\mathrm{s}}$ & $-2451.716436(-0.42)$ & -84.50 \\
\hline & 4 & $C_{2 \mathrm{v}}$ & -2300.089833 & \\
\hline \multirow[t]{7}{*}{ M052X/TZVP } & 1 & $C_{2}$ & $-3376.275732(0.00)$ & -97.46 \\
\hline & 1 & $C_{\mathrm{s}}$ & $-3376.276035(-0.19)$ & -94.66 \\
\hline & 2 & $C_{2}$ & $-3224.622086(0.00)$ & \\
\hline & 2 & $C_{\mathrm{s}}$ & $-3224.626850(-2.99)$ & \\
\hline & 3 & $C_{2}$ & $-2451.842595(0.00)$ & -83.17 \\
\hline & 3 & $C_{\mathrm{s}}$ & $-2451.843168(-0.36)$ & -83.53 \\
\hline & 4 & $C_{2 \mathrm{v}}$ & -2300.211732 & \\
\hline \multirow[t]{7}{*}{ B3LYP/6-31G* } & 1 & $C_{2}$ & $-3375.776025(0.00)$ & -98.71 \\
\hline & 1 & $C_{\mathrm{s}}$ & $-3375.775615(0.26)$ & -93.12 \\
\hline & 2 & $C_{2}$ & $-3224.171816(0.00)$ & \\
\hline & 2 & $C_{\mathrm{s}}$ & $-3224.180302(-5.33)$ & \\
\hline & 3 & $C_{2}$ & $-2451.577424(0.00)$ & -85.55 \\
\hline & 3 & $C_{\mathrm{s}}$ & $-2451.577304(0.08)$ & -85.48 \\
\hline & 4 & $C_{2 \mathrm{v}}$ & -2299.994176 & \\
\hline \multirow[t]{7}{*}{ BP86/def2-TZVP } & 1 & $C_{2}$ & $-3376.946342(0.00)$ & -98.04 \\
\hline & 1 & $C_{\mathrm{s}}$ & $-3376.946209(0.08)$ & -93.77 \\
\hline & 2 & $C_{2}$ & $-3225.257785(0.00)$ & \\
\hline & 2 & $C_{\mathrm{s}}$ & $-3225.264450(-4.18)$ & \\
\hline & 3 & $C_{2}$ & $-2452.444799(0.00)$ & -88.51 \\
\hline & 3 & $C_{\mathrm{s}}$ & $-2452.444536(0.17)$ & -88.35 \\
\hline & 4 & $C_{2 \mathrm{v}}$ & -2300.771418 & \\
\hline \multirow[t]{7}{*}{ M062X-D3/def2-QZVP//M052X/6-311++G** } & 1 & $C_{2}$ & $-3370.066352(0.00)$ & -102.81 \\
\hline & 1 & $C_{\mathrm{s}}$ & $-3370.066032(0.20)$ & -98.29 \\
\hline & 2 & $C_{2}$ & $-3218.422916(0.00)$ & \\
\hline & 2 & $C_{\mathrm{s}}$ & $-3218.429805(-4.32)$ & \\
\hline & 3 & $C_{2}$ & $-2445.820852(0.00)$ & -86.14 \\
\hline & 3 & $C_{\mathrm{s}}$ & $-2445.820179(0.42)$ & -85.72 \\
\hline & 4 & $C_{2 \mathrm{v}}$ & -2294.2039752 & \\
\hline
\end{tabular}

a Energy of OH radical in hartree - M052X/6-311++G** : -75.745970; M052X/TZVP : -75.7491633; B3LYP/6-31G* : 75.7234548; BP86/def2-TZVP : -75.766161; M062X-D3/def2-QZVP//M052X/6-311++G** : -75.7397975

$\Delta \mathrm{E}(\mathbf{1})=\mathrm{E}(\mathbf{1})-\mathrm{E}(\mathbf{2})-2 \mathrm{E}(\mathrm{OH})$

Similarly, the relative stability in $\mathbf{3}$ is obtained using

$\Delta \mathrm{E}(\mathbf{3})=\mathrm{E}(\mathbf{3})-\mathrm{E}(\mathbf{4})-2 \mathrm{E}(\mathrm{OH})$.

where $\mathrm{E}(\mathbf{1}), \mathrm{E}(\mathbf{2}), \mathrm{E}(\mathbf{3}), \mathrm{E}(\mathbf{4})$ and $\mathrm{E}(\mathrm{OH})$ are the total energies of $\mathbf{1}, \mathbf{2}, \mathbf{3}, \mathbf{4}$ and $\mathrm{OH}$ radical respectively. Figure 3 shows that the dicarbinolamine complex $\mathbf{1}$ is more stable than the stochiometrically equivalent component species $\mathbf{2}$ and two hydroxyl groups. The present study shows that the $C_{2}$ point group of $\mathbf{1}$ is favored energetically as compared to $\mathbf{2}\left(C_{2}\right)$ and two hydroxyl groups by 97.5 to $98.7 \mathrm{kcal} / \mathrm{mol}$ at M052X/6$311++\mathrm{G}^{* *}$, M052X/TZVP, BP86/def2-TZVP and
B3LYP/6-31G* levels of calculations. The corresponding relative stability in the $C_{\mathrm{s}}$ point group of $\mathbf{1}$ is 93.1 to $95.6 \mathrm{kcal} / \mathrm{mol}$ at the above DFT levels. The more authentic M062X/def2-QZVP//M052X/6$311++\mathrm{G}^{* *}$ calculations predict that $\mathbf{1}\left(C_{2}\right)$ and $\mathbf{1}\left(C_{\mathrm{s}}\right)$ are stabilized by 102.8 and $98.3 \mathrm{kcal} / \mathrm{mol}$, respectively, as compared to the respective components.

A similar trend in the relative stability is also observed with the dicarbinolamine complex 3. However, the relative stability in $\mathbf{3}$ is significantly lower than that in 1 as seen from Figure 3. The M062X-D3/ def2-QZVP//M052X/6-311++G** calculations predict the maximum decrease of $\sim 17 \mathrm{kcal} / \mathrm{mol}$ in the relative stability of $\mathbf{3}\left(C_{2}\right)$ as compared to that of $\mathbf{1}\left(C_{2}\right)$. 


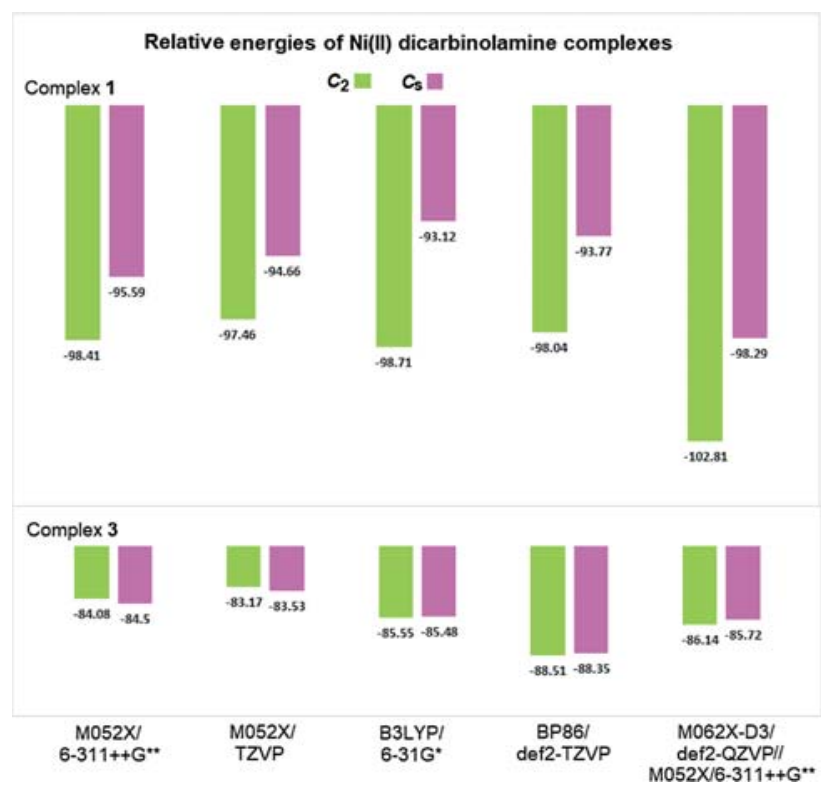

Figure 3. Relative stabilities of the dicarbinolamine complexes in $\mathrm{kcal} / \mathrm{mol}$ at different DFT levels.

The present comparative analysis shows that the presence of 4 phenyl substituents A, A', B and B' lead to additional stability in $\mathbf{1}$. The energy considerations clearly reveal that the dicarbinolamine complex is the stable species in comparison with the fully conjugated species.

The preferential stability in the dicarbinolamine complex $\mathbf{3}$ as compared to its components is also examined by computing the change in Gibbs free energy $\Delta \mathrm{G}$ at $298 \mathrm{~K}$ for the reaction

$\mathbf{3} \rightarrow \mathbf{4}+2(\mathrm{OH})$

$\Delta \mathrm{G}=\mathrm{G}(\mathbf{4})+2 \mathrm{G}(\mathrm{OH})-\mathrm{G}(\mathbf{3})$

$\mathrm{G}$ in the above equation denotes the Gibbs free energy. From the Gibbs free energies given in Table S6 (Supplementary Information), it is seen that the free energy changes are positive for the above reaction. ( 62.85 and $62.49 \mathrm{kcal} / \mathrm{mol}$ respectively for the $C_{2}$ and $C_{\mathrm{s}}$ structures of $\mathbf{3}$. The computed free energy change proves clearly the stability of the dicarbinolamine $\mathrm{Ni}(\mathrm{II})$ complex.

3.3a Natural bond orbital analysis: The role of the two axially oriented hydroxyl groups towards the stability of the dicarbinolamine complex can be understood by performing second-order perturbational energy analysis in natural bond orbital (NBO) basis. ${ }^{70,71}$ The stabilization energy associated with delocalization between a donor $\mathrm{NBO}(\mathrm{i})$ and acceptor $\mathrm{NBO}(\mathrm{j})$ is given as,
$\Delta \mathrm{E}_{\mathrm{ij}}=\mathrm{q}_{\mathrm{i}} \frac{\mathrm{F}(\mathrm{i}, \mathrm{j})^{2}}{\varepsilon \mathrm{j}-\varepsilon \mathrm{i}}$

where qi is the donor NBO occupancy, $\varepsilon i$ and $\varepsilon j$ are NBO energies and F(i,j) is the off-diagonal NBO Fock matrix element. The perturbational analysis of $\mathbf{1}$ reveals that there are significant stabilizing interactions that originate from the NBOs containing the oxygen atoms (of the hydroxyl groups). The role of the stabilizing second-order energy in the complexes of lithium and beryllium was reported earlier. ${ }^{58}$

The NBO analysis ${ }^{70,71}$ leads to classification of orbitals into core (CR), lone-pair (LP), Rydberg (RY) and localized bond (BD) orbitals. The corresponding antibonding orbitals are denoted $\mathrm{CR}^{*}, \mathrm{LP}^{*}, \mathrm{RY}^{*}$ and $\mathrm{BD}^{*}$, respectively. There are several second-order stabilising interactions between the donor type NBOs and the acceptor type NBOs. As the number of NBOs increase considerably with the increase in size of the basis set, we performed the NBO analysis at the B3LYP/6-31G* level using the G03W software and the B3LYP/6-31G* optimized geometries. All the interactions involving the oxygen atoms (from the $\mathrm{OH}$ groups in 1) having stabilisation energy $>0.1 \mathrm{kcal} / \mathrm{mol}$ are listed in Tables S7 and S8 (Supplementary Information), respectively, for the $C_{2}$ and $C_{\mathrm{s}}$ structures. The four major interactions which yield $>5 \mathrm{kcal} / \mathrm{mol}$ stabilization energy are presented in Table 2. It is seen that the second lone pair orbital $\mathrm{LP}(2)$ on each oxygen atom (donor NBO) interacts with the acceptor antibonding orbital $\mathrm{BD}^{*}(1)$ which is localized on the adjacent $\mathrm{C}-\mathrm{C}$ bond in the macrocyclic ring. Clearly, there are two such interactions and each leads to the stabilisation energy of $\sim 7 \mathrm{kcal} / \mathrm{mol}$ in both the $C_{2}$ and $C_{\mathrm{s}}$ structures. Further, the antibonding NBO of the $\mathrm{C}-\mathrm{O}$ bond $\mathrm{BD} *(1)$ behaves as an acceptor and interacts with the bonding $\mathrm{NBO} \mathrm{BD}(2)$ of the adjacent $\mathrm{C}-\mathrm{N}$ bond in the macrocycle and contributes a stability of 8.11 and $7.50 \mathrm{kcal} / \mathrm{mol}$, respectively in the $C_{2}$ and $C_{\mathrm{s}}$ structures of $\mathbf{1}$. The present NBO analysis reveals that the dicarbinolamine complex $\mathbf{1}$ possesses significant stability in view of the various donor-acceptor interactions originating from the oxygen atoms in the dicarbinol moiety as seen from Tables S7 and S8 (Supplementary Information).

3.3b Dispersion energies in the complexes 1, 2, 3 and 4: Table 3 lists the noncovalent dispersion energies in the complexes 1, 2, 3 and 4 obtained by performing single point M062X-D3/def2-QZVP calculation at the different DFT optimized geometries. The stabilizing dispersion energy is 
Table 2. Significant donor-acceptor NBO interactions involving the oxygen atoms of the hydroxyl groups in $\mathbf{1}$ yielding stabilization energy $>5 \mathrm{kcal} / \mathrm{mol}$.

\begin{tabular}{llcc}
\hline & & \multicolumn{2}{c}{ Stabilization energy (kcal/mol) } \\
\cline { 3 - 4 } Donor NBO & Acceptor NBO & $C_{2}$ & $C_{\mathrm{s}}$ \\
\hline LP (2) O1 & $\mathrm{BD}^{*}(1) \mathrm{C} 2-\mathrm{C} 1$ & 7.07 & 7.04 \\
LP (2) O2 & $\mathrm{BD}^{*}(1) \mathrm{C} 5-\mathrm{C} 6$ & 7.07 & 7.04 \\
BD (2) C3-N1 & $\mathrm{BD}^{*}(1) \mathrm{C} 2-\mathrm{O} 1$ & 8.11 & 7.50 \\
BD (2) C4-N2 & $\mathrm{BD} *(1)$ C5-O2 & 8.11 & 7.50 \\
\hline
\end{tabular}

Table 3. Dispersion energies in $\mathrm{kcal} / \mathrm{mol}$ in the complexes 1, 2, 3 and 4.

\begin{tabular}{|c|c|c|c|c|c|c|}
\hline \multicolumn{2}{|l|}{1} & \multicolumn{2}{|c|}{9} & \multicolumn{2}{|c|}{3} & \multirow{2}{*}{$\begin{array}{c}\mathbf{4} \\
C_{2 \mathrm{v}}\end{array}$} \\
\hline$C_{2}$ & $C \mathrm{~s}$ & $C_{2}$ & $C \mathrm{~s}$ & $C_{2}$ & $C \mathrm{~s}$ & \\
\hline \multicolumn{7}{|c|}{ M062X/def2-QZVP//M052X/6-311++G** } \\
\hline & ef2- & $\begin{array}{l}-4.52 \\
\mathrm{P} / / \mathrm{M} 0\end{array}$ & $\begin{array}{l}-4.5 \\
X / T Z\end{array}$ & -1.34 & -1.34 & -1.04 \\
\hline & -5 & -4.5 & -4 & -1.34 & -1.34 & -1.04 \\
\hline \multicolumn{7}{|c|}{ M062X/def2-QZVP//B3LYP/6-31G* } \\
\hline & $\begin{array}{l}-5.34 \\
\text { ef2-O }\end{array}$ & $\begin{array}{l}-4.51 \\
\mathrm{P} / / \mathrm{BP} 8\end{array}$ & $\begin{array}{l}-4.5 \\
/ \operatorname{def} 2-\end{array}$ & $\begin{array}{l}-1.34 \\
\text { VP }\end{array}$ & 1.34 & -1.0 \\
\hline & -5.3 & -4.50 & -4 & -1.35 & -1.34 & -1.0 \\
\hline
\end{tabular}

found to be the maximum in the bulky complex 1 having the values -5.28 and $-5.40 \mathrm{kcal} / \mathrm{mol}$, respectively, in the $C_{2}$ and $C_{\mathrm{s}}$ structures at M062X/ def2-QZVP//M052X/6-311++G** level. The corresponding dispersion stabilization in $2\left(C_{2}\right)$ and $2\left(C_{\mathrm{s}}\right)$ are -4.52 and $-4.56 \mathrm{kcal} / \mathrm{mol}$, respectively. As expected, ${ }^{50-52}$ the more crowded $C_{\mathrm{s}}$ structures of $\mathbf{1}$ and 2 have marginally more dispersion stabilization than that in the $C_{2}$ structures. The dispersion stabilization in $\mathbf{3}$ and $\mathbf{4}$ are found to be small having the values -1.34 and $-1.04 \mathrm{kcal} / \mathrm{mol}$, respectively, in agreement with their smaller size. ${ }^{58}$ Table 1 shows that the trends in the dispersion energies are similar for the geometries optimized at BP86 and B3LYP methods.

The origin of stability in the dicarbinolamine complexes was also examined in terms of the macrocyclic cavity size and the $\mathrm{Ni}$ - ligand covalency in the sections that follow. The large stabilization of $\mathbf{1}$ and $\mathbf{3}$ as compared to their components leads to the inference that similar macrocyclic dicarbinolamine complexes of different metals may also be stable.

\subsection{Macrocyclic cavity size}

The cavity size of the macrocyclic ligand has a decisive role in accommodating the metal ions. The extent of the metal-ligand bonding is related to the overlap of the orbitals of donor centres of the ligand with the orbitals of the central metal ion. This, in turn, depends on the orbital symmetries and on the cavity size of the macrocyclic ligand. The cavity size is smaller in the fully conjugated macrocyclic ligand than that of the corresponding ligand which is not completely conjugated. The metal-ligand interaction is strong when the macrocyclic cavity size is best suited for the efficient overlap of the orbitals of donor centres of the ligand with the metal orbitals. Table 4 compares the length and width of the macrocyclic unit in the optimized geometries of the $\mathrm{Ni}$ (II) complexes $\mathbf{1 - 4}$ as predicted by the different DFT methods. The length of the macrocycle is measured as the distance between the centres of the distal carbon atoms in the 6-membered chelate rings, C1...C6. The width of the macrocycle is the distance between opposite carbon atoms of the 5 -membered chelate rings $(\mathrm{C} 3 \ldots \mathrm{C} 8=\mathrm{C} 4 \ldots \mathrm{C} 7)$.

Table 4 shows that the M052X/6-311++G** predicted lengths and the widths of the macrocycle in the $C_{2}$ and $C_{\mathrm{s}}$ structures of 1 are 6.469 and $6.470 \AA$ and 5.175 and $5.167 \AA$, respectively. As expected, the mean length and width of 6.47 and $5.17 \AA$ in 1 are shorter than the observed values of 6.56 and $5.43 \AA$ in the crystal structure of low-spin $\mathrm{Ni}(\mathrm{II})$ complex having a 14-membered saturated tetraazamacrocyclic unit. ${ }^{25}$ The lengths in 2 are 6.375 and $6.285 \AA$, respectively, in the $C_{2}$ and $C_{\mathrm{s}}$ structures. Thus, the cavity length in $\mathbf{2}$ is shortened by 0.094 and $0.185 \AA$, respectively, in the $C_{2}$ and $C_{\mathrm{s}}$ structures as compared to that in $\mathbf{1}$. However, the predicted width of the macrocycle in $\mathbf{2}$ is increased by 0.103 and $0.040 \AA$ in the $C_{2}$ and $C_{\mathrm{s}}$ structures. The length of the cavity in $\mathbf{3}$ is decreased to $\sim 6.38 \AA$ as the steric repulsion from the phenyl groups on the distal carbons $\mathrm{C} 1$ and $\mathrm{C} 6$ are absent. The width of the macrocyclic cavity of $\mathbf{3}$ is not affected as compared to $\mathbf{1}$. In the case of $\mathbf{4}$, the length is shortened by $\sim 0.06 \AA$ while the width is increased by about 0.1 $\AA$ as compared to the values in the corresponding dicarbinol complex 3 . The increase of the width of the 
Table 4. Macrocyclic cavity length and width (in $\AA$ ) in the complexes $\mathbf{1 - 4}$.

\begin{tabular}{|c|c|c|c|c|c|c|c|}
\hline & \multicolumn{2}{|c|}{1} & \multicolumn{2}{|c|}{2} & \multicolumn{2}{|c|}{3} & \multirow{2}{*}{$\begin{array}{c}\mathbf{4} \\
\mathrm{C}_{2 v}\end{array}$} \\
\hline & $\mathrm{C}_{2}$ & $\mathrm{Cs}$ & $\mathrm{C}_{2}$ & $\mathrm{Cs}$ & $\mathrm{C}_{2}$ & $\mathrm{Cs}$ & \\
\hline \multicolumn{8}{|c|}{$\mathrm{M} 052 \mathrm{X} / 6-311++\mathrm{G}^{* *}$} \\
\hline Length & 6.469 & 6.470 & 6.375 & 6.285 & 6.381 & 6.385 & 6.323 \\
\hline Width & 5.175 & 5.167 & 5.278 & 5.207 & 5.187 & 5.171 & 5.288 \\
\hline \multicolumn{8}{|c|}{ M052X/TZVP } \\
\hline Length & 6.463 & 6.462 & 6.367 & 6.277 & 6.374 & 6.377 & 6.315 \\
\hline Width & 5.173 & 5.162 & 5.276 & 5.206 & 5.186 & 5.170 & 5.286 \\
\hline \multicolumn{8}{|c|}{ BP86/def2-TZVP } \\
\hline Length & 6.537 & 6.533 & 6.416 & 6.315 & 6.410 & 6.414 & 6.342 \\
\hline Width & 5.215 & 5.215 & 5.281 & 5.184 & 5.234 & 5.231 & 5.303 \\
\hline \multicolumn{8}{|c|}{ B3LYP/6-31G* } \\
\hline Length & 6.522 & 6.524 & 6.402 & 6.276 & 6.401 & 6.405 & 6.334 \\
\hline Width & 5.182 & 5.181 & 5.258 & 5.141 & 5.199 & 5.194 & 5.280 \\
\hline
\end{tabular}

macrocyclic cavity in $\mathbf{2}$ and $\mathbf{4}$ may be explained from the reorganization of the macrocyclic ring structure as compared to that in the dicarbinolamine complex. It is noticed that the bond lengths of $\mathrm{C} 3-\mathrm{N} 1$ and N4-C8 are longer than the values in the dicarbinolamine complexes. This will lead to an increase in the width of the macrocyclic part (C3...C8) in 2 and 4. The M052X/ TZVP, BP86/def2-TZVP and B3LYP/6-31G* methods also predict similar trend in the cavity size as seen from Table 4 . Though the cavity length is decreased in the fully conjugated systems $\mathbf{2}$ and $\mathbf{4}$ the width is more than that of the corresponding dicarbinolamine complex. Thus, the predicted cavity dimensions do not lead to any inference regarding the relative strengths of the metal-ligand bonds in the complexes under study.

\subsection{Covalent bond order and strength}

of the metal-ligand bonds in the complexes 1-4

The stability and reactivity of the inorganic complexes are controlled by the strength of the metal-ligand bonds. Covalent bond-order of the metal-ligand bond is the quantum chemical parameter which is fundamental to quantify the strength of the complex and hence its stability. The importance of metal-ligand covalency to explain stability and reactivity in the transition metal complexes is focused in recent studies. $^{33,34,47,48}$ Although the covalent bond-order is sensitive to the quantum chemical method of calculation, the values predicted by the same method for a series of related systems provide valuable insights in understanding the bonding in them. Larger the magnitude of the metal-ligand covalent bond order, stronger is the metal-ligand bonding. We have analyzed the covalent bond orders of the Ni-N bonds in the systems under study using the Mayer's bond orders. ${ }^{61-63}$ For consistency, we analyzed the bond orders predicted by the single-point M062X/def2QZVP calculations performed at geometries optimized by the M052X, BP86 and B3LYP methods. The results are presented in Table 5. It is seen from Table 5 that the bond orders predicted by M062X/def2-QZVP calculations vary from 0.40 to 0.63 . Clearly the bond order between the nickel ion and the chelating nitrogen is less than that of a normal covalent bond (bond order 1.0). Earlier studies showed a variation of covalent bond order from 0.2 to 0.7 for coordinate covalent metal-ligand bonds in metal complexes at different DFT levels. ${ }^{33,34,48,72-75}$ It was observed that the bond order for axial bonds are smaller than that of the equatorial bonds by BP86/def2-TZVP

Table 5. Meyer's covalent bond orders for Ni-N bonds in the complexes 1-4 as predicted by single point M062X/ def2-QZVP at different DFT optimized geometries.

\begin{tabular}{|c|c|c|c|c|c|c|c|}
\hline \multirow[b]{2}{*}{ Bond } & \multicolumn{2}{|c|}{1} & \multicolumn{2}{|c|}{2} & \multicolumn{2}{|c|}{3} & \multirow{2}{*}{$\begin{array}{c}\mathbf{4} \\
C_{2 \mathrm{v}}\end{array}$} \\
\hline & $C_{2}$ & $C \mathrm{~s}$ & $C_{2}$ & $C \mathrm{~s}$ & $C_{2}$ & $C \mathrm{~s}$ & \\
\hline \multicolumn{8}{|c|}{ M062X/def2-QZVP//M052X/6-311++G** } \\
\hline Ni-N1 & 0.63 & 0.62 & 0.50 & 0.46 & 0.63 & 0.62 & 0.50 \\
\hline Ni-N3 & & & & & 0.41 & & \\
\hline \multicolumn{8}{|c|}{ M062X/def2-QZVP// M052X/TZVP } \\
\hline $\mathrm{Ni}-\mathrm{N}$ & 0.62 & 0.61 & 0.50 & 0.46 & 0.63 & 0.61 & 0.50 \\
\hline $\mathrm{Ni}-\mathrm{N} 3$ & 0.44 & 0.49 & 0.47 & 0.47 & & & \\
\hline \multicolumn{8}{|c|}{ M062X/def2-QZVP//B3LYP/6-31G* } \\
\hline & & & & 0.48 & & & \\
\hline $\mathrm{Ni}-\mathrm{N} 3$ & 0.51 & 0.56 & 0.48 & 0.47 & 0.45 & 0.45 & 0.46 \\
\hline \multicolumn{8}{|c|}{ M062X/def2-QZVP// BP86/def2-TZVP } \\
\hline Ni-N1 & 0.60 & 0.59 & 0.50 & 0.47 & 0.60 & 0.59 & 0.50 \\
\hline $\mathrm{Ni}-\mathrm{N} 3$ & 0.52 & 0.55 & 0.48 & 0.47 & 0.46 & 0.45 & 0.46 \\
\hline
\end{tabular}


calculations. ${ }^{33,34}$ In the complexes under study, the two nickel-nitrogen bonds which are near to the benzo ring, Ni-N1 and Ni-N2, are equivalent by symmetry and possess same covalent bond order. Similarly the bonds Ni-N3 and Ni-N4 have same bond-order.

The magnitudes of the Ni-N covalent bond orders are found to correlate well with the Ni-N bond lengths in 1. At the M062X/def2-QZVP//M052X/6$311++\mathrm{G}^{* *}$ level the $\mathrm{Ni}-\mathrm{N} 1$ and $\mathrm{Ni}-\mathrm{N} 2$ bonds in $\mathbf{1}$, having shorter bond lengths of $\sim 1.84 \AA$ (Figure 1a), possess higher bond orders of $0.63\left(C_{2}\right)$ and $0.62(\mathrm{Cs})$ than the bonds $\mathrm{Ni}-\mathrm{N} 3$ and Ni-N4 with bond lengths $\sim 1.89 \AA$ and bond orders $0.44\left(C_{2}\right)$ and $0.48(\mathrm{Cs})$. Thus, the bond orders in the dicarbinolamine complex 1 reveal that the covalent bonding between the $\mathrm{Ni}$ ion and the nitrogen atoms closer to the benzo ring are stronger than those between the $\mathrm{Ni}$ ion and chelating nitrogen atoms $\mathrm{N} 3$ and N4. However, in the fully conjugated macrocyclic complex $\mathbf{2}$, though the four $\mathrm{Ni}-\mathrm{N}$ bond lengths vary from 1.86 to $1.88 \AA$ they possess similar bond orders in the range 0.46-0.50. The bond order analysis reveals that the Ni-N bonds in the dicarbinolamine complex $\mathbf{1}$ are overall stronger than those in the fully conjugated complex 2 . The bond orders presented in Table 5 show that the bonding features of the coordinating bonds in the complexes $\mathbf{3}$ and $\mathbf{4}$ are very similar to those of $\mathbf{1}$ and $\mathbf{2}$ respectively. Further, it is observed that the trends predicted above in the Ni-N bond orders in 1, 2, 3 and 4 at the M062X/def2-QZVP//M052X/6-311++G** level are in close agreement with the results generated with the geometries obtained at the different DFT levels examined in the present work (Table 5). The bond order analysis accounts for the better stability in $\mathbf{1}$ as compared to that of $\mathbf{2}$ which leads to the formation of the dicarbinolamine complex $\mathbf{1}$ as experimentally observed.

The strength of the $\mathrm{Ni}(\mathrm{II})$-ligand bonds in the experimentally observed dicarbinolamine complex $\mathbf{1}$ can be compared with related $\mathrm{Ni}(\mathrm{II})$ complexes having 14-membered tetraaza macrocyclic ligand. Earlier DFT study on $\mathrm{Ni}$ (II)-cyclam derivatives ${ }^{33}$ at BP86/def2-TZVP level in the gas-phase showed the bond order for equatorial $\mathrm{Ni}-\mathrm{N}$ bonds (bond lengths 1.95-1.99 ̊) are 0.65-0.67. The BP86/def2-TZVP bond orders for Ni-N1 and Ni-N3 bonds in $\mathbf{1}$ (bond lengths 1.86 and $1.84 \AA$ ) are 0.76 and 0.81 , respectively (Table S5, Supplementary Information). The higher bond orders in $\mathbf{1}$ at BP86/def2-TZVP level reveal that the Nickel-Nitrogen bonding is stronger in $\mathbf{1}$ as compared to that in the cyclam complexes wherein the macrocyclic ligand is fully saturated.

\subsection{Frontier molecular orbital analysis}

Figure 4 shows the highest occupied molecular orbital (HOMO), the next inner occupied orbital HOMO-1, lowest unoccupied molecular orbital (LUMO) and the next higher unoccupied orbital $\mathrm{LUMO}+1$ for the systems under study at the M052X/6-311++G** optimized geometries. It is seen that the HOMO-1 and HOMO are $\pi$-bonding MOs and the LUMO and LUMO +1 are $\pi^{*}$ antibonding MOs. In $\mathbf{1 - 4}$, the HOMO is a $\pi$ bonding MO which is delocalized mainly over the $\mathrm{Ni}$ and the chelating nitrogen atoms $\mathrm{N} 1, \mathrm{~N} 2, \mathrm{~N} 3$ and $\mathrm{N} 4$, the fused benzo ring and the ethene carbons $\mathrm{C} 7$ and $\mathrm{C} 8$. Though the HOMO is essentially similar in the four systems under study, it is observed that the contribution of overlapping $\mathrm{p}_{\mathrm{z}} \mathrm{AOs}$ in the Ni-N1 and Ni-N2 bonding regions is more pronounced than that of the Ni-N3 and Ni-N4 regions in $\mathbf{1}$ and $\mathbf{3}$. The population of valence atomic orbitals in the coordinating region as predicted by the natural population analysis is given in Table 6 . The population of $4 p_{z} A O$ on $\mathrm{Ni}(\mathrm{II})$ and $2 \mathrm{p}_{\mathrm{z}} \mathrm{AO}$ on $\mathrm{N} 1$ in $\mathbf{1}$ are 0.49 and 4.43 electron, respectively. The natural populations of the valence $\mathrm{p}_{\mathrm{z}}$ AOs in $\mathbf{3}$ are similar. The corresponding populations in $\mathbf{2}$ and $\mathbf{4}$ are lower $(0.43$ and 4.26). This accounts for the stronger Ni-N1 and $\mathrm{Ni}-\mathrm{N} 2$ bonds with higher covalent bond orders than the $\mathrm{Ni}-\mathrm{N} 3$ and Ni-N4 bonds in $\mathbf{1}$ and 3. Consequently, the bond lengths Ni-N1 and Ni-N2 are shorter than those of Ni-N3 and Ni-N4 as seen from Figure 1 and Tables S1 and S3 (Supplementary Information). However, in $\mathbf{2}$ and $\mathbf{4}$, the HOMO has nearly equal bonding contributions to the four $\mathrm{Ni}-\mathrm{N}$ bonds as
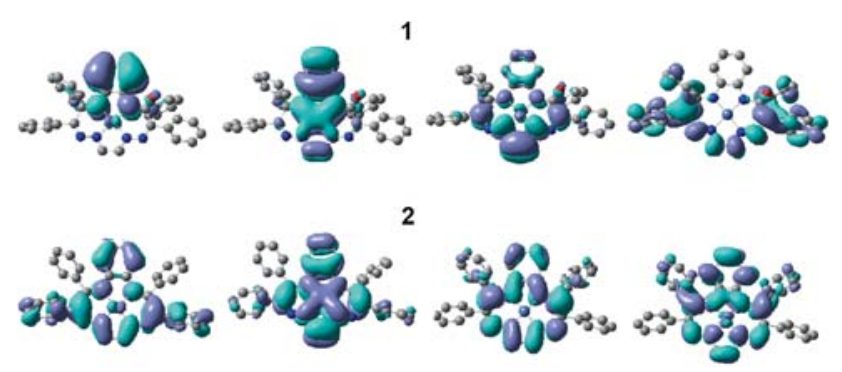

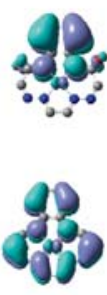

HOMO-1

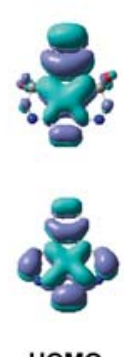

HOMO
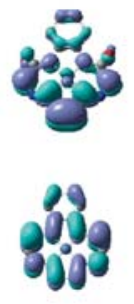

LUMO
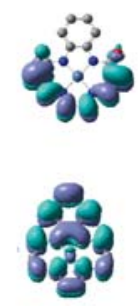

LUMO+1
Figure 4. Frontier molecular orbitals in 1, 2, 3 and 4 at the M052X/6-311++ $\mathrm{G}^{* *}$ optimized geometries. 
Table 6. Natural electronic population of valence orbitals of atoms at the coordinating region and their natural charges at M052X/6-311++G** level.

\begin{tabular}{|c|c|c|c|c|c|c|}
\hline \multirow[b]{2}{*}{ System } & \multirow[b]{2}{*}{ Point group } & \multirow[b]{2}{*}{ Element } & \multicolumn{3}{|c|}{ Natural population } & \multirow[b]{2}{*}{ Natural charge } \\
\hline & & & ns & $\mathrm{np}$ & $(n-1) d$ & \\
\hline \multirow[t]{5}{*}{1} & $C_{2}$ & $\mathrm{Ni}$ & 0.30 & 0.49 & 8.61 & 0.60 \\
\hline & & N1 & 1.27 & 4.43 & & -0.71 \\
\hline & & N3 & 1.30 & 3.94 & & -0.25 \\
\hline & & $\mathrm{O} 1$ & 1.67 & 5.09 & & -0.76 \\
\hline & & $\mathrm{C} 3$ & 0.82 & 3.07 & & 0.10 \\
\hline \multirow[t]{4}{*}{2} & $C_{2}$ & $\mathrm{Ni}$ & 0.32 & 0.43 & 8.63 & 0.62 \\
\hline & & N1 & 1.27 & 4.26 & & -0.53 \\
\hline & & N3 & 1.29 & 4.02 & & -0.31 \\
\hline & & $\mathrm{C} 3$ & 0.82 & 3.03 & & 0.14 \\
\hline \multirow[t]{5}{*}{3} & $C_{2}$ & $\mathrm{Ni}$ & 0.31 & 0.50 & 8.61 & 0.59 \\
\hline & & N1 & 1.27 & 4.39 & & -0.66 \\
\hline & & N3 & 1.32 & 3.94 & & -0.26 \\
\hline & & $\mathrm{O} 1$ & 1.68 & 5.06 & & -0.74 \\
\hline & & $\mathrm{C} 3$ & 0.81 & 3.03 & & 0.15 \\
\hline \multirow[t]{4}{*}{4} & $C_{2 \mathrm{v}}$ & $\mathrm{Ni}$ & 0.32 & 0.44 & 8.63 & 0.61 \\
\hline & & N1 & 1.27 & 4.26 & & -0.53 \\
\hline & & N3 & 1.29 & 4.02 & & -0.32 \\
\hline & & $\mathrm{C} 3$ & 0.82 & 3.03 & & 0.14 \\
\hline
\end{tabular}

predicted by similar covalent bond orders. The LUMOs of $\mathbf{1}$ and $\mathbf{3}$ are almost identical and are $\pi^{*}$ MOs having significant contribution from $\mathrm{Ni} \mathrm{d}_{\mathrm{yz}} \mathrm{AO}$. Though the LUMOs in $\mathbf{2}$ and $\mathbf{4}$ are also $\pi^{*}$ orbitals they do not have any contribution from the d-orbital on $\mathrm{Ni}$ centre and have different nodal patterns as compared to those of $\mathbf{1}$ and $\mathbf{3}$ (Figure 4). The HOMO-1, HOMO and LUMO of the complex 1 have negligible contribution from the four phenyl groups $\mathbf{A}, \mathbf{A}^{\prime}, \mathbf{B}$ and B'. It is seen that HOMO+1 of $\mathbf{1}$ is a $\pi^{*}$ MO delocalized over all the 4 phenyl rings. However, in complex 2, the HOMO has small contribution from the phenyl groups B and B' and the LUMO has contribution from $\mathbf{A}$ and $\mathbf{A}$ '. The HOMO-1 and the LUMO +1 have considerable contribution from $\mathbf{B}$ and B' and A and A', respectively.

\section{Conclusions}

The structural optimization reveals that the macrocyclic ligand unit is significantly nonplanar in the complexes $\mathbf{1}, \mathbf{2}$ and $\mathbf{3}$. The two hydroxyl groups in $\mathbf{1}$ and $\mathbf{3}$ are mainly responsible for the nonplanarity of the macrocyclic unit. The four phenyl groups $\mathbf{A}, \mathbf{A}^{\prime}$, $\mathbf{B}$ and $\mathbf{B}$ ' of the complexes $\mathbf{1}$ and $\mathbf{2}$ lie in vertical planes with reference to the plane of the macrocyclic ligand and thus, the steric repulsions are reduced. The dicarbinolamine complexes show large relative stability with reference to their fully saturated complexes as predicted by the DFT methods M052X/6-
311++G**, M052X/TZVP, BP86/def2-TZVP, B3LYP/6-31G* and M062X-D3/def2-QZVP//M052X/ 6-311++G**. The M062X-D3/def2-QZVP //M052X/ $6-311++\mathrm{G}^{* *}$ calculations show that the dicarbinolamine complexes $\mathbf{1}$ and $\mathbf{3}$ are stabilized by 102.8 and $86.1 \mathrm{kcal} / \mathrm{mol}$, respectively, with reference to their component species. NBO analysis reveals that in the dicarbinolamine complex there are significant secondorder stabilizing interactions originating from the NBOs containing the oxygen atoms. It is found that the four phenyl groups $\mathbf{A}, \mathbf{A}^{\prime}, \mathbf{B}$ and $\mathbf{B}^{\prime}$ in $\mathbf{1}$ lead to additional stability of $\sim 17 \mathrm{kcal} / \mathrm{mol}$.

Natural electronic population reveals that the $4 p$ orbital of $\mathrm{Ni}$ is populated by about 0.5 electrons in the dicarbinolamine complex $\mathbf{1}$ which is more than that in 2 (0.4 electron). Similarly, the $2 p$ population of coordinating nitrogen atoms closer to the benzo ring are more in $\mathbf{1}$ than that in $\mathbf{2}$. The HOMO of $\mathbf{1}$ reveals large $\pi$-bonding overlaps between the $\mathrm{Ni}$ and $\mathrm{N} 1$ as well as $\mathrm{Ni}$ and $\mathrm{N} 2$. Consequently, the Ni-nitrogen bonds in $\mathbf{1}$ are overall stronger than in $\mathbf{2}$ as predicted by the covalent orders which account for the formation of the dicarbinolamine complex 1 experimentally.

\section{Supplementary Information (SI)}

The DFT optimized structural parameters in the complexes 1, 2, 3 and 4 (Tables S1-S4), covalent bond orders at BP86/ def2-TZVP level (Table S5), Gibbs free energies in complexes 3 and 4 (Table S6) and second-order stabilization energy in $\mathbf{1}$ originating from the NBOs containing the 
oxygen atoms (Tables S7 and $\mathrm{S} 8$ ) are available at www.ias. ac.in/chemsci.

\section{References}

1. Huang X and Groves J T 2018 Oxygen activation and radical transformations in heme proteins and metalloporphyrins Chem. Rev. 1182491

2. Guo M, Corona T, Ray K and Nam W 2019 Synthesis of new tren-based heme and nonheme high-valent iron and manganese oxo cores in biological and abiological oxidation reactions ACS Cent. Sci. 513

3. Telser J, Horng Y C, Becker D F, Hoffman B M and Ragsdale S W 2000 On the assignment of nickel oxidation states of the Ox1 and Ox2 forms of methylcoenzyme M Reductase J. Am. Chem. Soc. 122182

4. Solomon E I, Brunold T C, Davis M I, Kemsley J N, Lee S-K, Lehnert N, Neese F, Skulan A J, Yang Y-S and Zhou J 2000 Geometric and electronic structure/function correlations in non-heme iron enzymes Chem. Rev. 100235

5. Solomon E I, Light K M, Liu L V, Srnec M and Wong S D 2013 Geometric and electronic structure contributions to function in non-heme iron enzymes Acc. Chem. Res. 462725

6. Hohenberger J, Ray K and Meyer K 2012 The biology and chemistry of high-valent iron-oxo and iron-nitrido complexes Nat. Commun. 3720

7. Cook S A and Borovik A S 2015 Molecular designs for controlling the local environments around metal ions Acc. Chem. Res. 482407

8. Shaik S, Kumar D, de Visser S P, Altun A and Thiel W 2005 Theoretical perspective on the structure and mechanism of cytochrome P450 enzymes Chem. Rev. 1052279

9. Goldberg D P 2007 Corrolazines: New frontiers in high-valent metalloporphyrinoid stability and reactivity Acc. Chem. Res. 40626

10. Liang X and Sadler P 2004 Cyclam complexes and their applications in medicine Chem. Soc. Rev. 33246

11. Wainwright K P 1997 Synthetic and structural aspects of the chemistry of saturated polyaza macrocyclic ligands bearing pendant coordinating groups attached to nitrogen Coord. Chem. Rev. 16635

12. Antunes P, Campello P M, Delgado R, Drew M G B, Felix V and Santos I 2003 Metal complexes of a tetraazacyclophane: Solution and molecular modelling studies Dalton Trans. 1852

13. Shircliff A D, Wilson K R, Cannon D J, Jones D G, Zhang Z, Chen Z, Yin G, Prior T J and Hubin T J 2015 Synthesis structural studies and oxidation catalysis of the manganese(II) iron(II) and copper(II) complexes of a 2-pyridylmethyl pendant armed side-bridged cyclam Inorg. Chem. Comm. 5971

14. Ranganathan R S, Raju N, Fan H, Zhang X, Tweedle M F, Desreux J F and Jacques V 2002 Polymethylated DOTA Ligands. 2. Synthesis of rigidified lanthanide chelates and studies on the effect of alkyl substitution on conformational mobility and relaxivity Inorg. Chem. 416856
15. Serres R G, Grapperhaus C A, Bothe E, Bill E, Weyhermüller T, Neese F and Wieghardt K 2004 Structural spectroscopic and computational study of an octahedral non-heme $\{\mathrm{Fe}-\mathrm{NO}\}$ 6-8 series: $[\mathrm{Fe}(\mathrm{NO})($ cyclamac) $] 2+/+/ 0$ J. Am. Chem. Soc. 1265138

16. Lauffer R B 1987 Paramagnetic metal complexes as water proton relaxation agents for NMR imaging: Theory and design Chem. Rev. 87901

17. Tweedle M F 1989 In Lanthanide probes in life, chemical and earth sciences: Theory and practice J-C G Bünzli and G R Choppin (Eds.) (New York: Elsevier) p. 127

18. Wang X, Jaraquemada-Peláez M G, Rodríguez-Rodríguez C, Cao Y, Buchwalder C, Choudhary N, Jermilova U, Ramogida C F, Saatchi K, Häfeli U O, Patrick B O and Orvig $\mathrm{C} 2018 \mathrm{H}_{4}$ octox: Versatile bimodal octadentate acyclic chelating ligand for medicinal inorganic chemistry J. Am. Chem. Soc. 14015487

19. Fur M L, Beyler M, Lepareur N, Fougère O, PlatasIglesias C, Rousseaux O and Tripier R 2016 Pyclen trin-butylphosphonate ester as potential chelator for targeted radiotherapy: From yttrium(III) complexation to 90Y radiolabeling Inorg. Chem. 558003

20. Ibrahim R, Tsuchiya S and Ogawa S 2000 A colorswitching molecule: Specific properties of new tetraaza macrocycle zinc complex with a facile hydrogen atom J. Am. Chem. Soc. 12212174

21. Francke R, Schille B and Roemelt M 2018 Homogeneously catalyzed electroreduction of carbon dioxidemethods mechanisms and catalysts Chem. Rev. 1189 4631

22. Félix V, Costa J, Delgado R, Drew M G. B. Duarte M T, Resende C 2001 X-Ray diffraction and molecular mechanics studies of 12-13- and 14-membered tetraaza macrocycles containing pyridine: effect of the macrocyclic cavity size on the selectivity of the metal ion J. Chem. Soc. Dalton Trans. 1462

23. Leugger A P, Hertli L and Kaden T A 1978 Metal complexes with macrocyclic ligands. XI. Ring size effect on the complexation rates with transition metal ions Helv. Chim. Acta $\mathbf{6 1} 2296$

24. Comba P and Schiek W 2003 Fit and misfit between ligands and metal ions Coord. Chem. Rev. 21238

25. Comba P, Lampeka Y D, Nazarenko A Y, Prikhod'ko A I, Pritzkow H and Taraszewska J 2002 Cooperative effects in the binding of substrates to bis-macrocyclic ligand nickel(II) and nickel(III) complexes Eur. J. Inorg. Chem. 1871

26. Barefield E K, Bianchi A, Billo E J, Connolly P J, Paoletti P, Summers J S and Van Derveer D G 1986 Thermodynamic and structural studies of configurational isomers of $\left[\mathrm{Ni}(\text { cyclam) }]^{2+}\right.$ Inorg. Chem. 254197

27. Kent B E 2010 Coordination chemistry of $N$-tetraalkylated cyclam ligands - A status report Coord. Chem. Rev. 2541607

28. Mochizuki K and Kondo T 1995 Isolation and Visabsorption spectrum of trans- $\left[\mathrm{Ni}\left(\mathrm{OH}_{2}\right)_{2}(-\right.$ cyclam) $] \mathrm{Cl}_{2} \cdot 4 \mathrm{H}_{2} \mathrm{O}$ Inorg. Chem. 346241

29. Choi K Y, Kim Y J, Ryu H and Suh I H 1999 Synthesis and characterization of nickel(II) complexes of a tetraaza macrocycle containing axial ligands Inorg. Chem. Commun. 2176 
30. Zeigerson E, Bar I, Bernstein J, Kirschenbaum L J and Meyerstein D 1982 Stabilization of the tervalent nickel complex with meso-5 771214 14-hexamethyl-1 48 11-tetraazacyclotetradecane by axial coordination of anions in aqueous solution Inorg. Chem. 2173

31. Bosnich B, Poon C K and Tobe M L 1965 Complexes of cobalt(III) with a cyclic tetradentate secondary amine Inorg. Chem. 41102

32. Meyer K, Bendix J, Bill E, Weyhermüller $\mathrm{T}$ and Wieghardt K 1998 Molecular and electronic structure of nitridochromium(V) complexes with macrocyclic amine ligands Inorg. Chem. 375180

33. Anuradha S, Malar E J P and Vijayaraghavan V R 2015 Kinetic measurements and quantum chemical calculations on low spin $\mathrm{Ni}$ (II)/(III) macrocyclic complexes in aqueous and sulphato medium J. Chem. Sci. 1271287

34. Sankaran A, Malar E J P and Vijayaraghavan V R 2017 Study of behaviour of Ni(III) macrocyclic complexes in acidic aqueous medium through kinetic measurement involving hydrogen peroxide oxidation and DFT calculations J. Chem. Sci. 129193

35. Barefield E K, Wagnor F and Hodges K D 1976 Synthesis of macrocyclic tetramines by metal ion assisted cyclization reactions Inorg. Chem. 151370

36. Busch D H and Bailar J C Jr 1956 The iron(II)-methine chromophore J. Am. Chem. Soc. 781137

37. Eggleston D S and Jackels S C 1980 Tetrasubstituted [14]-13810-tetraenen4 macrocyclic complexes: Synthesis organic precursor and template reaction mechanism Inorg. Chem. 191593

38. Haque Z P, McPartlin M and Tasker P A 1979 Macrocyclic ligand synthesis. Isolation of a dicarbinolamine complex from zinc(II)-promoted cyclization reaction Inorg. Chem. 182920

39. Balasubramanian S 1987 Macrocyclic dicarbinolamine complexes of nickel(II) with planar N4(N2) ligands: Synthesis and spectral and electrochemical properties Inorg. Chem. 26553

40. Sprung M A 1940 A Summary of the reactions of aldehydes with amines Chem. Rev. 26297

41. Jencke W P 1969 Catalysis in chemistry and enzymology (New York: McGraw Hill)

42. Parr R G and Yang W 1989 Density functional theory of atoms and molecules (New York: Oxford University)

43. Becke A D 1988 Density-functional exchange energy approximation with correct asymptotic behaviour Phys. Rev. A 383098

44. Perdew J P 1986 Density functional approximation for the correlation energy of the inhomogeneous electron gas Phys. Rev. B 338822

45. Schweinfurth D, Krzystek J, Schapiro I, Demeshko S, Klein J, Telser J, Ozarowski A, Su C Y, Meyer F, Atanasov M, Neese F and Sarkar B 2013 Electronic structures of octahedral Ni(II) complexes with "click" derived triazole ligands: a combined structural magnetometric spectroscopic and theoretical study Inorg. Chem. 526880

46. Petrenko T, Ray K, Wieghardt K and Neese F 2006 Vibrational markers for the open-shell character of transition metal bis-dithiolenes: an infrared resonance Raman and quantum chemical study J. Am. Chem. Soc. 1284422
47. Pollock C J, Delgado-Jaime M U, Atanasov M, Neese $\mathrm{F}$ and DeBeer S $2014 \mathrm{~K} \beta$ mainline X-ray emission spectroscopy as an experimental probe of metal-ligand covalency J. Am. Chem. Soc. 1369453

48. Fritsch N, Wick C R, Waidmann T, Dral P O and Tucher J 2014 Multiply bonded metal(II) acetate (rhodium ruthenium and molybdenum) complexes with the trans-12-bis(N-methylimidazol-2yl)ethylene ligand Inorg. Chem. 5312305

49. London F 1937 The general theory of molecular forces Trans. Faraday Soc. 33 8b

50. Liptrot D J and Power P P 2017 London dispersion forces in sterically crowded inorganic and organometallic molecules Nature Rev. Chem. 10004

51. Wagner J P and Schreiner P R 2015 London dispersion in molecular chemistry -reconsidering steric effects Angew. Chem. Int. Ed. 5412274

52. Wagner J P and Schreiner P R 2016 London dispersion decisively contributes to the thermodynamic stability of bulky NHC-coordinated main group compounds $J$. Chem. Theor. Comput. 12231

53. Zhao Y, Schultz N E and Truhlar D G 2006 Design of density functionals by combining the method of constraint satisfaction with parametrization for thermochemistry thermochemical kinetics and noncovalent interactions J. Chem. Theor. Comput. 2364

54. Zhao Y and Truhlar D G 2008 The M06 suite of density functionals for main group thermochemistry thermochemical kinetics noncovalent interactions excited states and transition elements: Two new functionals and systematic testing of four M06-class functionals and 12 other functionals Theor. Chem. Acc. 120215

55. Grimme S 2011 Density functional theory with London dispersion corrections WIREs Comput. Mol. Sci. 1211

56. Goerigk L, Grimme S 2011 A thorough benchmark of density functional methods for general main group thermochemistry kinetics and noncovalent interactions Phys. Chem. Chem. Phys. 136670

57. Rezac J and Hobza P 2016 Benchmark calculations of interaction energies in noncovalent complexes and their applications Chem. Rev. 1165038

58. Malar E J P and Divya P 2018 Structural stability in dimer and tetramer clusters of 1-alanine in the gasphase and the feasibility of peptide bond formation $J$. Phys. Chem. B 1226462

59. Becke A D 1993 Density-functional thermochemistry. III. The role of exact exchange J. Chem. Phys. 985648

60. Lee C, Yang W and Parr R G 1988 Development of the Colle-Salvetti correlation-energy formula into a functional of the electron density Phys. Rev. B 37785

61. Mayer I 1983 Charge bond order and valence in the ab initio SCF theory Chem. Phys. Lett. 97270

62. Mayer I 1984 Bond order and valence: Relations to Mulliken's population analysis Int. J. Quant. Chem. 26 151

63. Mayer I 1985 Bond orders and valences in the SCF theory: A comment Theor. Chim. Acta 67315

64. Frisch M J et al. 2004 GAUSSIAN 03 Revision E.01 (Wallingford CT: Gaussian Inc.)

65. Neese F 2003 An improvement of the resolution of the identity approximation for the formation of the coulomb matrix J. Comp. Chem. 241740 
66. Weigend F and Ahlrichs R 2005 Balanced basis sets of split valence triple zeta valence and quadruple zeta valence quality for $\mathrm{H}$ to $\mathrm{Rn}$ : Design and assessment of accuracy Phys. Chem. Chem. Phys. 73297

67. Weigend F 2006 Accurate coulomb-fitting basis sets for H to Rn Phys. Chem. Chem. Phys. 81057

68. Neese F 2012 The ORCA program system Wiley Interdiscip. Rev.: Comput. Mol. Sci. 273

69. Neese F 2018 Software update: The ORCA program system Version 4.0. Wiley Interdiscip. Rev.: Comput. Mol. Sci. 8 e 1327

70. Foster J P and Weinhold F J 1980 Natural hybrid orbitals J. Am. Chem. Soc. 1027211

71. Glendening E D, Reed A E, Carpenter J E and Weinhold F 1990 NBO Version 3.1 (Wisconsin: University of Wisconsin)

72. Malar E J P 2003 Do penta- and decaphospha analogues of lithocene anion and beryllocene exist?
Analysis of stability structure and bonding by hybrid density functional study Inorg. Chem. 42 3873

73. Malar E J P 2004 Can the cyclo-P5 ligand introduce basicity at the transition metal center in metallocenes? A hybrid density functional study on the cyclo-P5 analogues of metallocenes of $\mathrm{Fe}, \mathrm{Ru}$ and $\mathrm{Os}$ Eur. J. Inorg. Chem. 2723

74. Malar E J P 2005 Density functional theory analysis of some triple-decker sandwich complexes of iron containing cyclo-P5 and cyclo-As5 ligands Theor. Chem. Acc. 114213

75. Indubala E, Dhanasekar M, Sudha V, Malar E J P, Divya P, Sherine J, Rajagopal R, Bhat S V and Harinipriya S 2018 L-Alanine capping of $\mathrm{ZnO}$ nanorods: Increased carrier concentration in $\mathrm{ZnO} / \mathrm{CuI}$ heterojunction diode $R S C A d v .85350$ 